\title{
Sunglint images of current gradients at high resolution: Critical angle and directional observing strategy
}

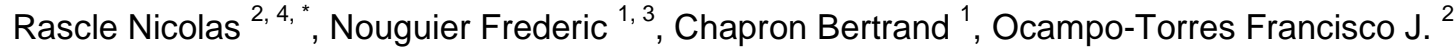

${ }^{1}$ Univ. Brest, CNRS, IRD, Ifremer, Laboratoire d'Océanographie Physique et Spatiale (LOPS), IUEM, Brest, France

${ }^{2}$ Departamento de Oceanografía Física, Centro de Investigación Científica y de Educación Superior de Ensenada, Baja California, México

${ }^{3}$ Université de Toulon, CNRS/INSU, IRD, Mediterranean Institute of Oceanography (MIO), UM 110, La Garde 83957, France

* Corresponding author : Nicolas Rascle, email address : $\underline{\text { nrascle@cicese.mx }}$

\begin{abstract}
:
High-resolution satellite images of the ocean surface in and around the sunglint often provide unique observations of sub-mesoscale upper ocean surface processes. Local anomalies of wind, waves, currents or surfactants appear on the images as local anomalies of brightness. A quantitative interpretation of those brightness anomalies must relate them to slope properties of the wave field, which are to the lowest order described by the mean square slope (mss).
\end{abstract}

The prevailing paradigm for such interpretation is that of the critical zenith angle. It states that, for subcritical zenith view angle, brightness and mss anomalies have opposite signs, and this defines the socalled inversion region. This prevailing paradigm implicitly builds on the assumption that the mss decomposition between upwind and crosswind components is conserved. The mss anomalies are then isotropic and can be reduced to a scalar (i.e. one-dimensional) quantity. In such a case, one single sunglint image would be sufficient to retrieve the mss anomaly. This isotropic case likely applies for surface wave changes induced by varying wind speed or by surfactants.

Yet, satellite and airborne observations at multiple view angles recently revealed anisotropic mss anomalies, e.g. with mss increase in the upwind direction and decrease in the crosswind direction. This anisotropic behavior likely characterizes wave modulations by anisotropic surface current gradients. This paper details the expected properties of such anisotropic mss modulations. It is shown that: 1) The classical concept of critical angle does not systematically hold, neither for frontal current shear nor for internal wave divergence. 2) At least two sunglint images at different zenith and azimuth angles are needed to retrieve the mss anomalies, and a single observation is not sufficient. 3) A satellite with radiometers looking at multiple zenith angles is capable of providing a geometry favorable to retrieve mss anomalies. An illustration is discussed with internal waves observed by the Multi-angle Imaging SpectroRadiometer (MISR), where the upwind and crosswind components of the retrieved mss anomalies are anisotropic. Those results provide guidelines to interpret available observations and to 
help refine strategy for future satellite missions.

\section{Highlights}

- Sunglint images can provide wind and current variations at very high resolution. The concept of critical angle usually relates brightness to wave slopes. The concept does not systematically hold for all surface current variations. The use of multi-angle observations is often necessary to quantify current gradients. A strategy for future satellite sunglint missions is proposed.

Keywords: Sea surface roughness, Surface current gradients, Submesoscale turbulence, Wavecurrent interaction, Surfactants, Sun glint imagery, SAR images, Multi-angle radiometers, Surface slope distribution, Mean square slope 


\section{Introduction}

Upper ocean deformations at fine horizontal scales $(\sim 1 \mathrm{~km})$ include effects associated to internal waves, submesoscale fronts and filaments whose roles for vertical exchanges with the ocean interior and for the dispersion of horizontal tracers are numerously highlighted by both theoretical and high resolution numerical modelling studies (Spall, 1995; Nagai et al., 2006; Thomas et al., 2008; Klein and Lapeyre, 2009; Zhong and Bracco, 2013; Callies et al., 2015; Brannigan et al., 2015; Brannigan, 2016). Consequently, proper understanding of the marine biochemical and ecological functioning, as well as improved quantification of the impact of fine scale vertical exchanges of heat, gas and carbon on climatic scales, hinges on our ability to observe and estimate the upper ocean dynamics at fine resolution (Ferrari, 2011; Perruche et al., 2011; Lévy et al., 2012). Ambitious field experiments have recently been undertaken to do so (Özgökmen et al., 2014; Shcherbina et al., 2015; D’ Asaro et al., 2018), but there is still a lack of more systematic means of observing the ocean dynamics at these fine horizontal scales. Efforts to remedy this situation using satellite observations are under way, with the upcoming Surface Water and Ocean Topography (SWOT) mission (Fu et al., 2012) and with the proposed Wavemill (Buck, 2005; Martin and Gommenginger, 2017) and/or Sea Surface KInematics Multiscale monitoring (SKIM) concepts (Ardhuin et al., 2017a) using radar Doppler information (Chapron et al., 2005; Johannessen et al., 2008).

In that context, the more direct use of surface roughness images has been largely overlooked, whereas with large footprints and high resolution capabilities, surface roughness images can already be valuable to further improve qualitative and quantitative understandings of upper ocean processes at fine scale (Johannessen et al., 2005; Kudryavtsev et al., 2012a; Rascle et al., 2014, 2017). In particular, images of sea surface roughness are routinely obtained using optical radiometers viewing areas in and around the sunglint (e.g Apel et al., 1975). Under low to moderate wind conditions, surface roughness images often spectacularly picture a wide range of surface phenomena at scales of about $10 \mathrm{~m}$ to $30 \mathrm{~km}$, including oceanic internal waves, fronts and filaments (e.g. Fett and Rabe, 1977; La Violette et al., 1980), atmospheric wind rolls and fronts (e.g. Vandemark et al., 2001), surface swell wave transformation (e.g. Kudryavtsev et al., 2017b), and surface slicks and oil spills (Soules, 1970).

Those phenomena appear as local brightness anomalies on the images because local anomalies of currents, wind and surfactants can strongly affect small scale (capillaries and short gravity) waves under moderate wind conditions (Kudryavtsev et al., 2005). In principle, it is thus possible to track and quantify gradients of surfactants, gradients of wind (thus ocean-atmosphere interactions at high resolution) and gradients of currents (thus wave-current interactions at high resolution) (Kudryavtsev et al., 2005).

The location of the brightness anomalies, and their time evolution if successive observations are available, contain a very rich geophysical information and has been consistently used in past studies (e.g. Matthews, 2005; Jackson, 2007). Yet, much more information can be unveiled if brightness can be related to roughness directional and statistical properties of the wave field, which are to lowest order described using the wave mean square slope (mss) parameter (Kudryavtsev et al., 2017a). In most sunglint analysis, it is customary to assume that sunglint images are divided into two regions by a critical angle (e.g McClain and Strong, 1969; Jackson and Alpers, 2010; Matthews, 2005; Kudryavtsev et al., 2012b). At large incidence angle, the brightness and mss anomaly have similar signs, whereas at lower incidence angle, they have opposite signs. The latter region is the so-called inversion region (see e.g. fig. 1a).

Recent observations suggest that this classical analysis (i.e. using the concept of critical angle) does not systematically hold for sunglint images of currents (Rascle et al., 2016, 2017). A new framework of interpretation of those images is thus needed, together with a new observational strategy. This is the purpose of the present paper.

We first recall in section 2 that the classical critical angle relies on a strong assumption. It is indeed assumed that the mss decomposition between upwind and crosswind slope components is conserved. The mss anomalies are then nearly isotropic and can be reduced to a scalar (i.e. one-dimensional) quantity. In such a case, one single sunglint image is sufficient to retrieve the mss anomaly, provided that the incidence angle differs from the critical angle. This classical isotropic case is probably valid to analyze varying wind conditions or surfactants (e.g Chust and Sagarminaga, 2007).

In section 3, we reproduce recent observations at multiple view angles from satellite (Rascle et al., 2016) and airplane (Rascle et al., 2017). Those observations show that mss anomalies can be anisotropic (i.e. two-dimensional), for instance with mss increase in the upwind direction and decrease in the crosswind direction. Such anisotropic mss anomalies are likely characteristic of roughness modulations by anisotropic current gradients, e.g. current shear or strain (Rascle et al., 2014), whereas isotropic mss anomalies are likely characteristic of isotropic current divergence. 
We detail the expected properties of such anisotropic mss anomalies to show that the classical concept of critical angle does not systematically hold, neither for frontal current shear nor for internal wave divergence.

As the mss anomalies can independently scale in two directions, at least two sunglint images at different zenith and azimuth angles are then needed to retrieve the mss anomalies. In such a case, a single sunglint image is not sufficient. Assuming the wind direction to be the principal axis, section 4 discusses the best viewing geometry and shows that a satellite with radiometers viewing at multiple zenith angles is capable of providing a favorable geometry.

In section 5, internal waves observed by the Multi-angle Imaging SpectroRadiometer (MISR, Diner et al., 1989) are analyzed. The upwind and crosswind components of the mss anomalies are retrieved and again display measurable anisotropy. Discussion and guidelines for interpretation are found in section 6. An observational strategy for future sunglint missions is proposed in section 7.

\section{Classical critical angle}

In this section, we recall the equations of sunglint analysis and the main hypothesis behind the classical concept of critical angle.

\subsection{Sea surface radiance and surface slope $P D F$}

The radiance received by the sensor can be described as (e.g. Kay et al., 2009)

$$
B=B_{A T M}+L_{a t m}\left(B_{S u n G}+B_{S k y G}+B_{W L}+B_{W C}\right),
$$

where $B_{A T M}$ is the atmospheric radiance, $B_{S \text { un }}$ is the sunglint radiance, $B_{S k y G}$ is the skyglint radiance, $B_{W L}$ is the water leaving radiance, $B_{W C}$ is the radiance due to whitecaps, and $L$ is the atmospheric transmittance.

We consider the surface brightness field in the sunglint area, where the other sources of radiance are negligible, i.e. $B \simeq L_{a t m} B_{\text {Sun }}{ }^{1}$. Following the standard analysis of Cox and Munk (1954), the sunglint radiance, $B_{S \text { unG }}$, generated by specular reflection of the sun light is given as

$$
B_{\text {SunG }}=\frac{\rho E_{s}}{4 \cos \theta_{c} \cos ^{4} \theta_{r}} P\left(z_{x r}, z_{y r}\right)
$$

where $E_{s}$ is the solar irradiance at the surface, $\rho$ is the Fresnel reflection coefficient, $P\left(z_{x}, z_{y}\right)$ is the 2D probability density function (PDF) of surface slopes $z_{x}$ and $z_{y}$, and $z_{x r}$ and $z_{y r}$ denote their values satisfying the conditions of specular reflections of the sun light received by the camera,

$$
z_{x r}=-\frac{\sin \theta_{s} \cos \varphi_{s}+\sin \theta_{c} \cos \varphi_{c}}{\cos \theta_{s}+\cos \theta_{c}}, z_{y r}=-\frac{\sin \theta_{s} \sin \varphi_{s}+\sin \theta_{c} \sin \varphi_{c}}{\cos \theta_{s}+\cos \theta_{c}}
$$

where $\theta_{c}$ and $\theta_{s}$ are the camera and sun zenith incidence angles, and $\varphi_{c}$ and $\varphi_{s}$ are the camera and sun azimuth angles. Those slopes define the zenith $\theta_{r}$ and azimuth $\varphi_{r}$ angles of the facets providing specular reflection, with $\tan \theta_{r}=\sqrt{z_{x r}^{2}+z_{y r}^{2}}$ and $\tan \varphi_{r}=z_{y r} / z_{x r}$.

To ease the demonstration, the local slope PDF is taken as a 2D gaussian with the major axes in the upwind and crosswind directions, it is written as

$$
P\left(z_{x}, z_{y}\right)=\frac{1}{2 \pi \sqrt{m_{u} m_{c}}} \exp \left(-\frac{z_{x}^{2}}{2 m_{u}}-\frac{z_{y}^{2}}{2 m_{c}}\right),
$$

where the local mean square slopes are $m_{u}$ and $m_{c}$ in the upwind and crosswind directions, respectively.

\footnotetext{
${ }^{1}$ In clear sky conditions, this is true up to zenith facet angles $\theta_{r}$ about $20^{\circ}$ to $25^{\circ}$, depending on the wind speed (Cox and Munk, 1954 ) and on the sensor wavelength. At larger angles, water leaving radiance, skyglint (e.g. Lin et al., 2016) and whitecaps (e.g. Frouin et al., 1996) become increasingly important.
} 


\subsection{Local anomalies of radiance and of wave slopes}

Estimation of the sunglint radiance $B_{S u n G}$ at each pixel of an image can provide the mss, which is related to the wind speed (Cox and Munk, 1954), an extremely valuable information (e.g. Bréon and Henriot, 2006). Such estimation of $B_{S u n G}$ requires estimations of the atmospheric transmittance $L_{a t m}$ and of the solar irradiance $E_{s}$ at the surface (e.g. Gatebe et al., 2005; Harmel and Chami, 2013). This difficulty will be avoided here by focusing on local radiance variations relative to the background radiance of the surrounding regions on the images.

Following Kudryavtsev et al. (2012b), the radiance $B=B_{0}+d B$ is separated into a slowly varying background $B_{0}$ and a local anomaly $d B$ by horizontally filtering at a scale $L$. $L$ is chosen much smaller than the camera elevation, such that at scales smaller than $L$, the viewing angles can be considered constant. A notable exception would be images obtained from multiple adjacent sensors with different look angles (e.g. Sentinel-2, Kudryavtsev et al., 2017a).

The local radiance contrast is then entirely due to the local PDF contrast,

$$
\frac{d B}{B}=\frac{d P}{P},
$$

where we note that the atmospheric transmittance is no longer needed. In turn, the local PDF contrast is related to local variations of currents, wind or surfactants. To extract geophysical information from the sunglint images, the problem is to retrieve the mss contrasts $d m_{u} / m_{u}$ and $d m_{c} / m_{c}$ from the PDF contrast $d P / P$.

Again assuming that the PDF is nearly gaussian, or at least that the PDF contrast is dominated by changes in the slope variance with the major axes in the upwind and crosswind direction, small variations of $m_{u}$ and $m_{c}$ lead to (see also Eq. 5a and 5b in Kudryavtsev et al., 2012b):

$$
\frac{d P}{P}=\frac{1}{2}\left[\left(\frac{z_{x}^{2}}{m_{u}}-1\right) \frac{d m_{u}}{m_{u}}+\left(\frac{z_{y}^{2}}{m_{c}}-1\right) \frac{d m_{c}}{m_{c}}\right] .
$$

\subsection{Isotropic mss contrasts}

Following measurements of Cox and Munk (1954) of clean water and surface slicks, Kudryavtsev et al. (2012b) considered as a first approximation that the directionality ratio $\alpha=m_{c} / m_{u}$ is not modified by surface slicks ${ }^{2}$. This can be written as

$$
\frac{d m}{m}=\frac{d m_{u}}{m_{u}}=\frac{d m_{c}}{m_{c}},
$$

where $m$ is the total mean square slope, $m=m_{u}+m_{c}$. The background mss might not be isotropic (i.e. $\alpha \neq 1$ ), but its variations are isotropic. The mss contrast can then be considered as a scalar quantity and the PDF is quasi one-dimensional (e.g. Jackson and Alpers, 2010; Kudryavtsev et al., 2012b; Matthews, 2005; Matthews and Awaji, 2010; He et al., 2015; Yang et al., 2015).

The transfer function $T$ between radiance contrast and mss contrast, defined by

$$
\frac{d B}{B}=T \frac{d m}{m},
$$

reduces to

$$
T=\left(-1+\frac{z_{x}^{2}}{2 m_{u}}+\frac{z_{y}^{2}}{2 m_{c}}\right) .
$$

\footnotetext{
${ }^{2}$ See for example the decomposition of eq. 13. The mss measurements of Cox and Munk (1954) indicate that, in the case of transition from clean water to surface slicks under constant wind, $d m_{a} / m_{a}$ is less than $15 \%$ of $d m_{s} / m_{s}$ for wind greater than $3.5 \mathrm{~m} \mathrm{~s}^{-1}$. In other words, $d m / m \simeq d m_{s} / m_{s}$ and $\alpha$ can be supposed constant. A wind modification by the slicks (e.g. Mitsuyasu and Honda, 1986) is probably included in the measurements of Cox and Munk (1954), and is unlikely to invalidate this approximation.
} 


\subsection{Critical angle}

The transfer function (eq. 9) thus defines two zones (fig. 1) in the $\left(z_{x}, z_{y}\right)$ domain, separated by an ellipse. Outside the ellipse $(T>0)$, brightness contrast co-varies with the same sign as the mss contrast. At variance, inside the ellipse $(T<0)$, brightness and mss present inverted contrasts. That latter zone is called the contrast inversion zone, and it is easily recognizable on sunglint images because surface slicks appear as bright contrasts instead of dark contrasts (see e.g. Kudryavtsev et al., 2012b, their fig. 2).

The ellipse itself defines the so-called critical angle $\theta_{r, \text { crit }}$. That angle can be approximated by $\theta_{r, c r i t} \simeq \arctan (\sqrt{m})$, with its exact values comprised between $\arctan \left(\sqrt{2 m_{c}}\right)$ and $\arctan \left(\sqrt{2 m_{u}}\right)$ in the crosswind and upwind directions, respectively. Fig. 1c shows those angles computed using mss values from Cox and Munk (1954). Under moderate wind speeds of $5-10 \mathrm{~m} \mathrm{~s}^{-1}$, where the majority of sunglint images occur, the critical angle takes values about $\theta_{r, \text { crit }} \simeq 8-12^{\circ}$.
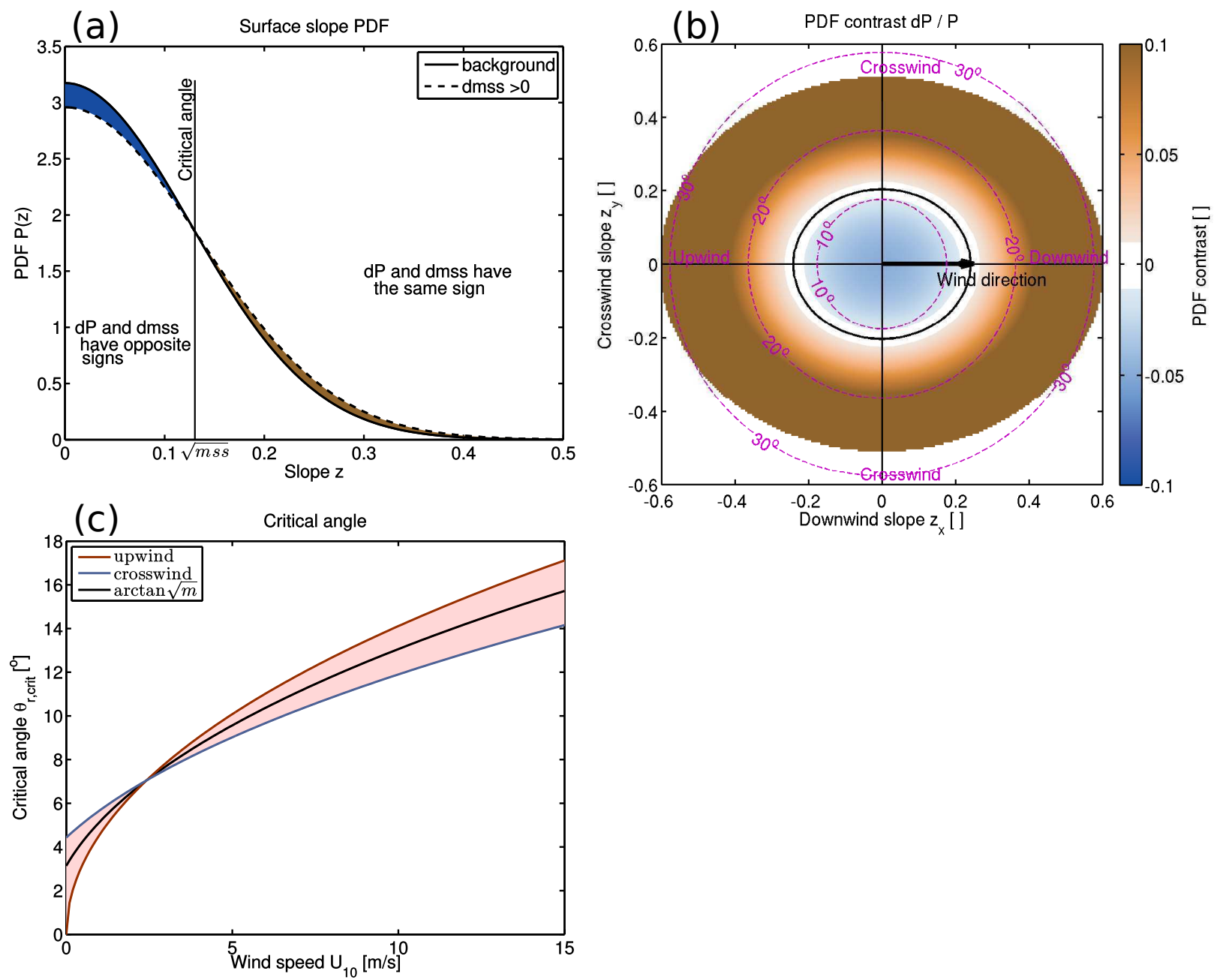

Figure 1: (a) One-dimensional sketch of surface slope PDF variation for an increase of mss, showing the critical angle and the inversion zone. (b) Two-dimensional PDF contrast $d P / P$, as function of the surface slopes $\left(z_{x}, z_{y}\right)$, for an isotropic mss contrast of $d m / m=+5 \%$. Here we use background mss values from Cox and Munk (1954) for a $9 \mathrm{~m} \mathrm{~s}^{-1}$ wind speed, i.e. $m_{u}=0.028$ and $m_{c}=0.020$. As a noise limit of sunglint radiance, contrasts are not shown for $P<0.01$. Pink contours are values of $\theta_{r}$. (c) Critical angle $\theta_{r, c r i t}$ as function of the wind speed, according to mss values of Cox and Munk (1954). 


\subsection{Single-angle observation}

In the case of isotropic mss variations, a unique observation of $d B / B$ at one viewing angle $\left(z_{x r}, z_{y r}\right)$ is thus enough to retrieve $d m / m$, provided that the viewing angle is far from the critical angle because the transfer function (9) vanishes in the vicinity of the ellipse.

For practical use, a single satellite image is then sufficient. Kudryavtsev et al. (2012b) used this method to successfully retrieve mss variations due to surface slicks inside and outside the contrast inversion zone.

\section{Directional mss contrasts}

In this section, observational evidences of anisotropic mss contrasts are demonstrated to discuss the expected properties of such contrasts.

\subsection{Observations of azimuthal contrast inversion}

Analyzing sunglint images from two different satellites, Rascle et al. (2016) documented a case of contrast inversion between two observations at similar zenith view angles $\theta_{r}$ but orthogonal azimuth view angles $\varphi_{r}$ (fig. 2a). Using airplane measurements, Rascle et al. (2017) obtained observations with a quasi-complete coverage of the different view angles, and confirmed the presence of azimuthal contrast inversion (fig. 2b). Such azimuthal inversions cannot be explained by isotropic mss variations, as shown with the black ellipses on fig. 2 (the interested reader is referred for more details to the aforementioned papers). Those observations demonstrate that mss contrasts can be anisotropic, i.e. two-dimensional, with upwind and crosswind mss contrasts not related by (7).
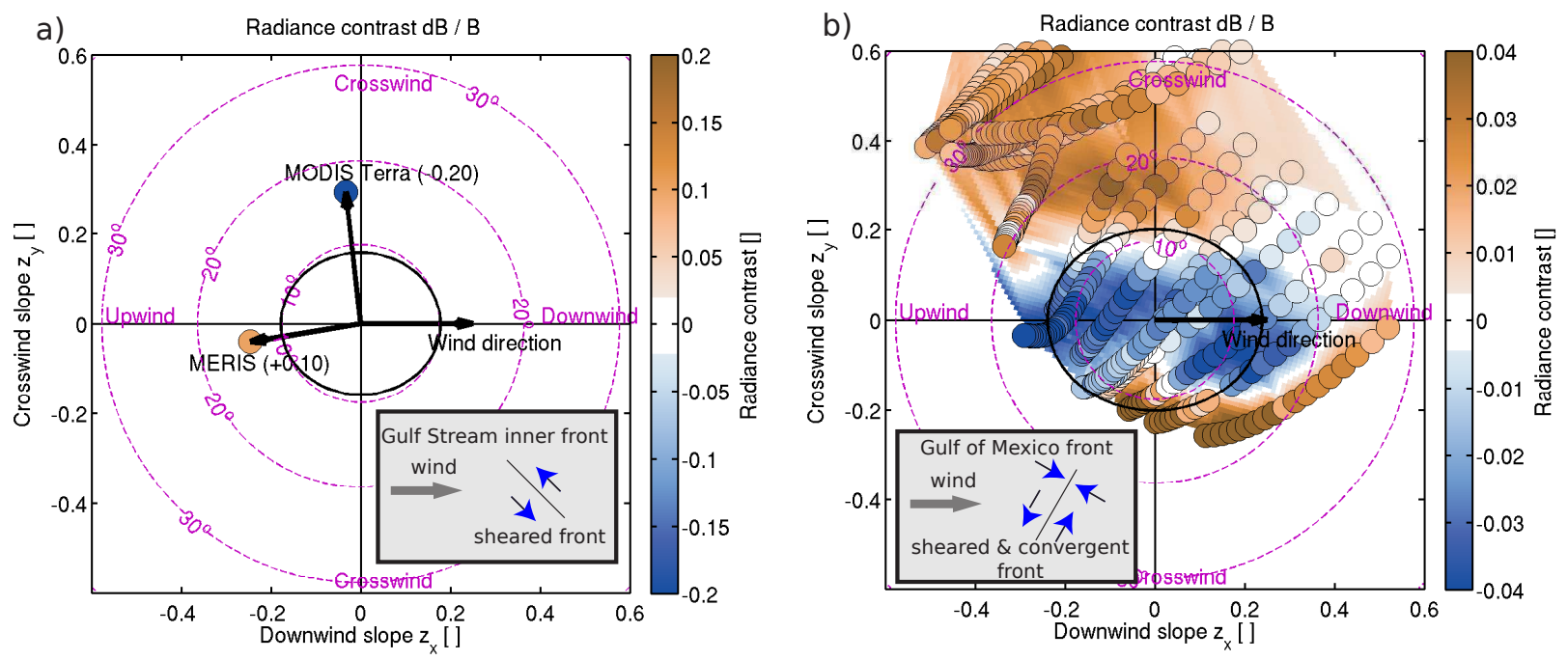

Figure 2: (a) Radiance contrasts of the Gulf Stream inner front, observed from two different satellites on 1st April 2010. See Rascle et al. (2016) for details. (b) Radiance contrasts over a front in the Gulf of Mexico, observed from airplane on 11th February 2016. Each dot represent one observation, and a filled colored shape is used to improve visibility, see Rascle et al. (2017) for details. The expected critical angle is shown with the black ellipses for wind speeds of 5 and $9 \mathrm{~m} \mathrm{~s}^{-1}$, respectively in (a) and (b). The insets show sketches of the current feature and of the wind direction.

\subsection{Antisymmetric mss contrasts}

Complementary to the isotropic case of section 2 , the case of antisymmetric mss contrasts is

$$
\frac{d m_{u}}{m_{u}}=-\frac{d m_{c}}{m_{c}} .
$$

In such a case, the transfer function $T$ defined by

$$
\frac{d B}{B}=T \frac{d m_{u}}{m_{u}}
$$


reduces to

$$
T=\frac{1}{2}\left(\frac{z_{x}^{2}}{m_{u}}-\frac{z_{y}^{2}}{m_{c}}\right) .
$$

The condition $T=0$ defines two strait lines in the $\left(z_{x}, z_{y}\right)$ domain, and thus eq. (12) defines four zones of different azimuth angles (fig. 3a).
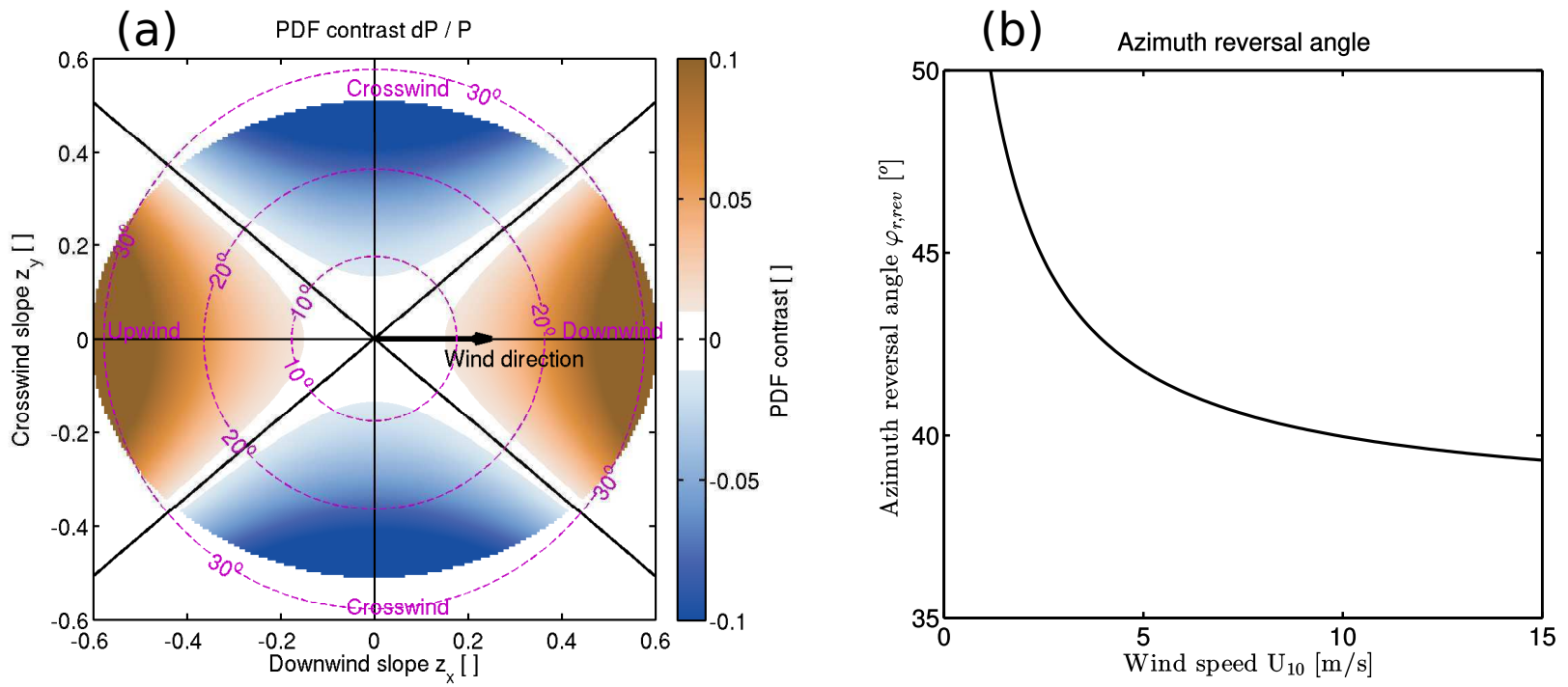

Figure 3: (a) Surface slope PDF contrast for an antisymmetric mss contrast of $+2.5 \%$ upwind and $-2.5 \%$ crosswind. Here we use background mss values from Cox and Munk (1954) for a $9 \mathrm{~m} \mathrm{~s}^{-1}$ wind speed. (b) Azimuth angle between the wind and the lines of contrast reversal in the antisymmetric case, for different values of the wind speed and according to mss values of Cox and Munk (1954).

For such antisymmetric mss contrasts, the classical contrast inversion zone does not exist, nor does a critical zenith angle. On the contrary, the important parameter becomes the azimuth angle with respect to the wind direction. The contrast reversal occurs at an azimuth angle of $\varphi_{r, \text { rev }}= \pm \arctan \left(\sqrt{m_{c} / m_{u}}\right)$ with respect to the wind direction, which is about $40-45^{\circ}$ (depending on the wind speed, see fig. $3 b$ ).

To note, a unique observation of $d B / B$ at one viewing angle $\left(z_{x r}, z_{y r}\right)$ is still enough to retrieve the mss contrast $d m_{u} / m_{u}$, provided that the viewing angle is far from the two strait lines where the transfer function (12) vanishes (fig. 3a).

\subsection{General case: anisotropic mss contrasts}

In the general case, any anisotropic mss anomaly can be decomposed onto the two modes previously described, the isotropic (symmetric) mode $m_{s}$ and the antisymmetric mode $m_{a}$, by writing

$$
\frac{d m_{s}}{m_{s}}=\frac{1}{2}\left[\frac{d m_{u}}{m_{u}}+\frac{d m_{c}}{m_{c}}\right], \frac{d m_{a}}{m_{a}}=\frac{1}{2}\left[\frac{d m_{u}}{m_{u}}-\frac{d m_{c}}{m_{c}}\right] .
$$

The radiance contrast can thus be rewritten as

$$
\frac{d P}{P}=\frac{1}{4}\left(-2+\frac{z_{x}^{2}}{m_{u}}+\frac{z_{y}^{2}}{m_{c}}\right) \frac{d m_{s}}{m_{s}}+\frac{1}{4}\left(\frac{z_{x}^{2}}{m_{u}}-\frac{z_{y}^{2}}{m_{c}}\right) \frac{d m_{a}}{m_{a}} .
$$

Under our hypothesis that the principal axis of the slope PDF remains aligned with the wind direction, we obtain thereby any possible mss anomaly (fig. 4).

Note that instead of decomposing the mss variations into isotropic and antisymmetric variations (fig. 4a), we could have used the canonical decomposition into upwind and crosswind variations (fig.4b). However variations of the PDF 
in only one direction are of little practical use since the most common variation is the isotropic one. An example of such a use will be given in section 5 .
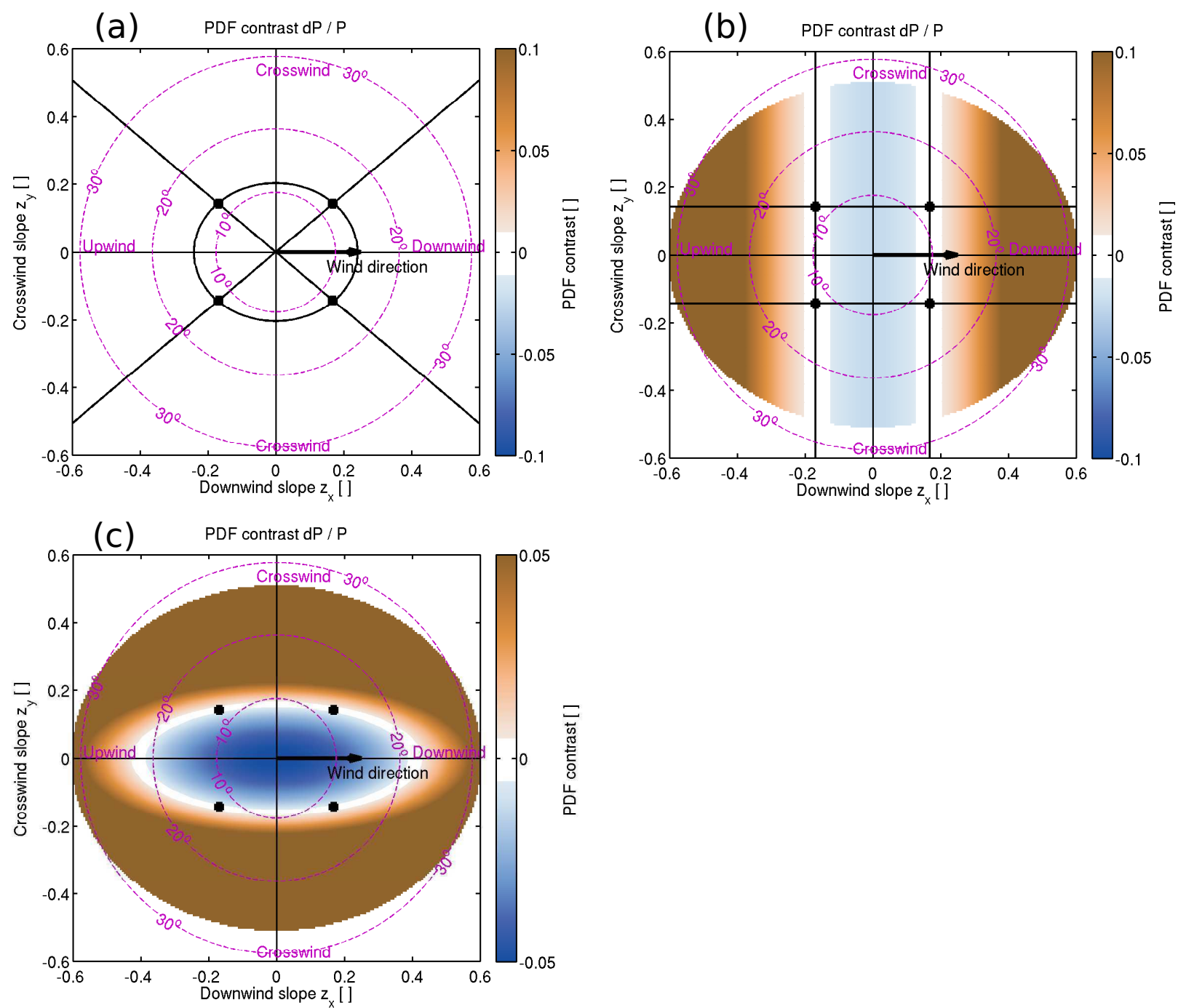

Figure 4: (a) Lines where the surface slope PDF contrast $d P / P$ vanishes for isotropic (black ellipse) and antisymmetric (black lines) mss contrasts. Observations at viewing angles corresponding to the four black dots would contain no geophysical information. (b) Lines where the PDF contrast vanishes for the upwind (vertical black lines) and crosswind (horizontal black lines) mss contrasts. The colors show PDF contrast for an upwind mss contrast of $+5 \%$. (c) Example of anisotropic variations with an upwind mss contrast of $+2 \%$ and a crosswind contrast of $+9 \%$, which was found to fit the airplane data of fig. $2 b$.

\section{Observational strategy}

In this section, we discuss an observational strategy to estimate anisotropic mss variations.

\subsection{Specification of the multi-look angles}

Since there are two unknowns, the upwind $d m_{u} / m_{u}$ and crosswind $d m_{c} / m_{c}$ mss contrasts, at least two observations $d P_{1} / P_{1}$ and $d P_{2} / P_{2}$ at different angles $\left(z_{x r 1}, z_{y r 1}\right)$ and $\left(z_{x r 2}, z_{y r 2}\right)$ are required. To retrieve the mss contrast, the system 


$$
\left[\begin{array}{l}
\frac{d P_{1}}{P_{1}} \\
\frac{d P_{2}}{P_{2}}
\end{array}\right]=T\left[\begin{array}{l}
\frac{d m_{u}}{m_{u}} \\
\frac{d m_{c}}{m_{c}}
\end{array}\right]
$$

with the transfer function tensor

$$
T=\frac{1}{2}\left[\begin{array}{cc}
\frac{z_{x r 1}^{2}}{m_{u}}-1 & \frac{z_{y r 1}^{2}}{m_{c}}-1 \\
\frac{z_{x x 2}^{2}}{m_{u}}-1 & \frac{z_{y r 2}^{2}}{m_{c}}-1
\end{array}\right]
$$

The transfer function tensor needs to be invertible, i.e. the condition on the determinant writes as

$$
\left(\frac{z_{x r 1}^{2}}{m_{u}}-1\right)\left(\frac{z_{y r 2}^{2}}{m_{c}}-1\right)-\left(\frac{z_{y r 1}^{2}}{m_{c}}-1\right)\left(\frac{z_{x r 2}^{2}}{m_{u}}-1\right) \neq 0 .
$$

The singular curves of the isotropic and antisymmetric modes are drawn in fig. 4a. We note that:

- The four observational points with $\left|z_{x r}\right|=\sqrt{m_{u}}$ and $\left|z_{y r}\right|=\sqrt{m_{c}}$ contain no geophysical information on the mss contrasts, as they are singular for the two modes.

- If one observation is strictly on the ellipse, it cannot capture the isotropic mode. The second observation needs to be within or outside the ellipse.

- Two orthogonal azimuth view angles at similar zenith angles, as often used by scatterometers, are at times sufficient but more view angles are needed to systematically capture both modes.

The locations of the singularities for the two modes depend on the background wind speed and direction, according to fig. $1 \mathrm{c}$ and $3 \mathrm{~b}$.

\subsection{Azimuth facet diversity from zenith camera diversity}

Satellites using different cameras at different zenith angles have proven very useful by providing time sequences of sunglint images (e.g. Matthews and Yoshikawa, 2012). Due to the bistatic nature of sunglint measurements, those satellites can also provide a multi-angle geometry favorable to directional mss retrieval. An example obtained from the Multi-angle Imaging SpectroRadiometer (MISR, Diner et al., 1989) on-board the satellite Terra can illustrate it. MISR provides multiple observations of the same surface target using 9 cameras oriented at 9 different zenith angles, $+70^{\circ},+60^{\circ},+46^{\circ},+26^{\circ}$ (forward), $0^{\circ}$ (nadir), and $-26^{\circ},-46^{\circ},-60^{\circ}$ and $-70^{\circ}$ (aftward), respectively for cameras \#1 to \#9. The geometry is described in fig. 5a for an ocean target off South Africa located vertically below the satellite orbit on 16 Dec. 2012. The satellite overflies the target in a descending track from the northeast to the southwest. The 9 observations are separated in time by less than 7 minutes. As Terra is a morning sun-synchronous satellite, the sun is located at the northeast of the target. The resulting reflective facets exhibit both different zenith $\theta_{r}$ and azimuth $\varphi_{r}$ angles, providing a favorable multi-angle geometry to capture the two modes (isotropic and antisymmetric) of mss contrasts.

Nonetheless, the large zenith angle differences between successive MISR cameras (about $20^{\circ}$ ) still provides a poor angular discretization of the observations. For instance, only 4 sunglint observations (\#4, \#5, \#6 and \#7) occur at $\theta_{r}<$ $25^{\circ}$, which is the usual range of validity of sunglint images with negligible sky reflection. The angular discretization of the Advanced Spaceborne Thermal Emission and Reflection Radiometer (ASTER) cameras (e.g. Matthews, 2005) or the Panchromatic Remote-sensing Instrument for Stereo Mapping (PRISM) cameras (e.g. Matthews and Awaji, 2010) are of similar order (fig. 5c). A more specifically designed sunglint mission would thus benefit from a higher angular discretization. The one of the future Multi-Viewing Multi-Channel Multi-Polarization Imaging Mission (3MI) sensor (Manolis et al., 2013) shown in fig. 5b would be well suited, but we note that the spatial resolution of the sensor (about $4 \mathrm{~km}$ at nadir) will be insufficient as it will only capture large current structures. 
(a)



(b) Angles of Reflective Facet for 3MI

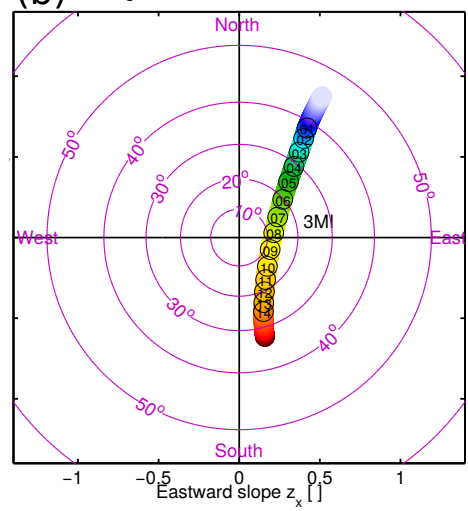

(C) Angles of Reflective Facet for PRISM

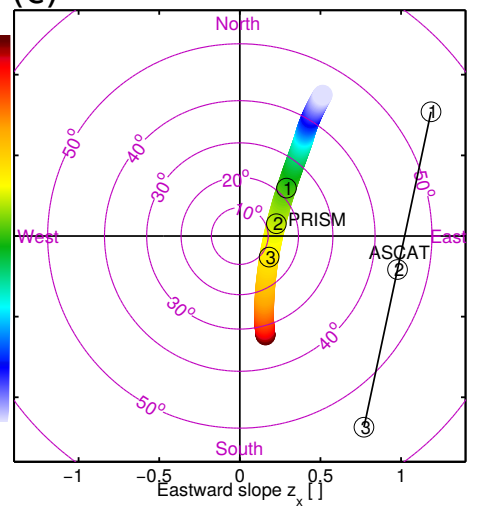

Figure 5: (a) Synthesis of the geometry of the observations with MISR, for a point located below the satellite orbit off South Africa (20 $0^{\circ}$, $-35.5^{\circ} \mathrm{N}$ ) on $16 \mathrm{Dec}$. 2012. The satellite flies from the northeast to the southwest (descending track), capturing the scene with its 9 cameras at different view angles, and within a few minutes. The sun is located towards the northeast as Terra is on a sun-synchronous morning orbit. The resulting reflective facets have different zenith and azimuth angles. (b) Facet angles at which the future 3MI sensor would acquire for the same scene. (c) Facet angles at which PRISM would have acquired. For comparison, the multi-look capability of the ASCAT scatterometer is also shown for a surface target located at the center of its swath.

\section{Illustration: Internal waves over the Agulhas region}

Hereafter, the MISR capability of multi-angle measurements is shown to help quantify mss contrasts induced by internal waves. Again, those mss contrasts are found to be anisotropic.

\subsection{Multi-angle images}

IW trains over the Agulhas region are detected on 16 Dec. 2012 at 8:45 UTC (fig. 6). The $672 \mathrm{~nm}$ radiance observations from MISR is selected at 9 different angles. These 9 observations are separated in time by less than 7 minutes (see fig. 5) and can be considered quasi-simultaneous at the time scale of the observed oceanic features. The images have a spatial pixel resolution of about $275 \mathrm{~m}$. The radiance contrast is obtained by high-pass filtering with a cut-off horizontal scale of $L=5 \mathrm{~km}$. 

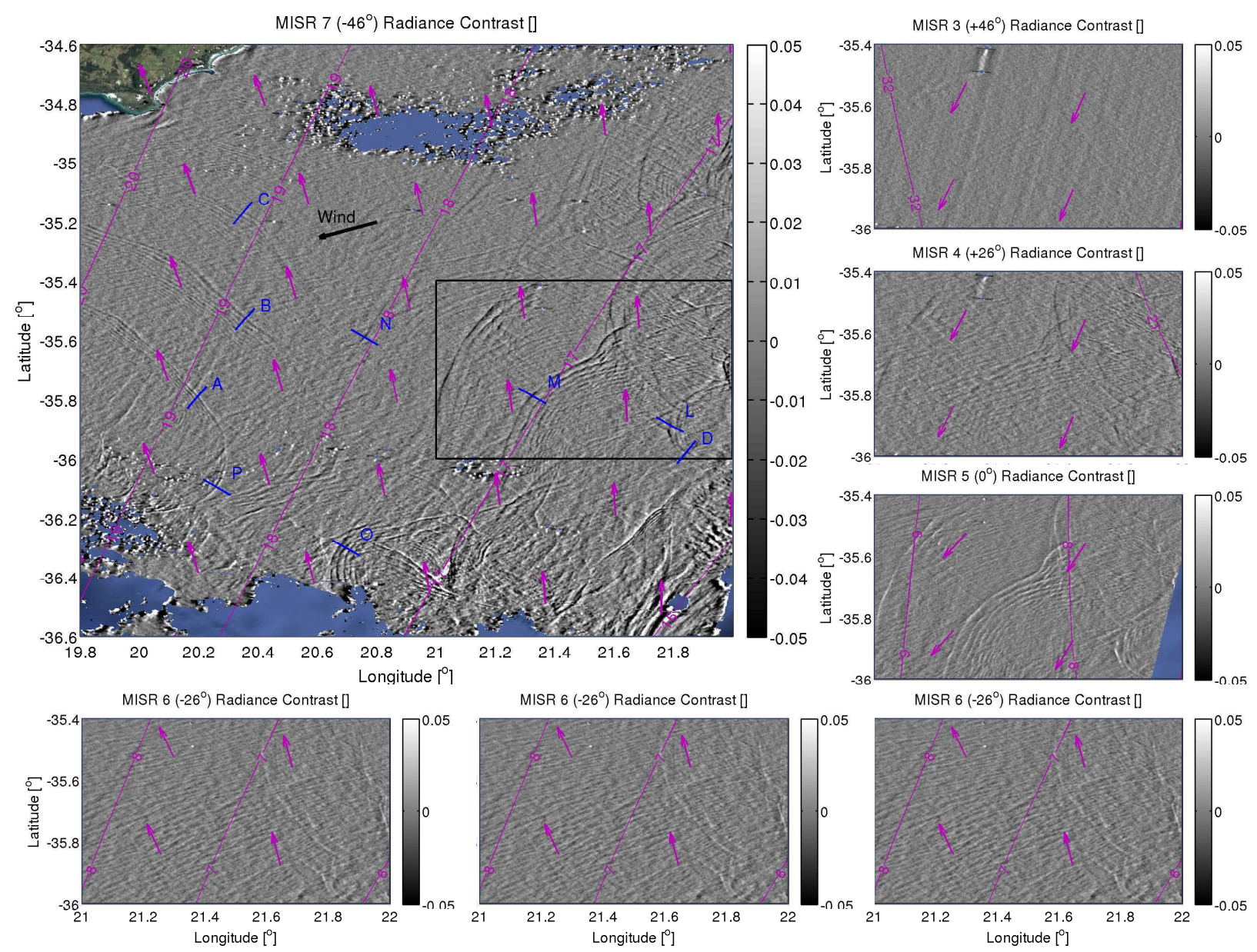

Figure 6: MISR radiance contrast in the Agulhas region off South Africa, on 16 Dec. 2012 at 8:45 UTC. The large image shows the radiance contrast for the $-46^{\circ}$ (aftward) camera. Small images show a zoom on the region highlighted in black, for the cameras at $+46^{\circ},+26^{\circ}$, nadir, $-26^{\circ}$, $-46^{\circ}$ and $-60^{\circ}$. Pink contours and arrows show zenith $\theta_{r}$ and azimuth $\varphi_{r}$ view angles.

The wind was blowing from the east-northeast (ENE; with an azimuth angle of $\varphi \simeq 75^{\circ}$ relative to the north), as evidenced by the presence of aligned wind streaks (Vandemark et al., 2001) on the image (fig. 6). Numerical meteorological reanalysis (ERA interim, Dee et al., 2011) and nearby scatterometer measurements at 03:12 UTC and 15:00 UTC (ASCAT, SAF, 2013) both confirm light winds in the area, about $5 \mathrm{~m} \mathrm{~s}^{-1}$ (not shown).

Multiple trains of internal waves (IWs) can be identified on the image. We focus our analysis on four IW trains propagating in the northeast/southwest direction (A, B, C, D), and five IW trains propagating in the northwest/southeast direction (L, M, N, O, P).

\subsection{Anisotropic mss contrasts}

The radiance contrasts $d B / B$ produced by IWs is calculated as the contrast difference between converging and diverging zones. Converging (diverging) zones are defined as zones of positive (negative) contrast at large zenith view angle $\theta_{r}$, respectively. The contrasts are shown in fig. 7 as functions of the view angles. As expected from classical critical angle analysis, surface current convergence produces positive radiance contrast at large zenith view angle $\theta_{r}$, and negative radiance contrast at small zenith angle. The ellipse of classical critical angle is shown in black. The classical critical angle provides a first order agreement with the observations.

However there is a clear departure of the contrast inversion area from the classical critical angle. For instance, the change of sign of IW contrast between the camera \#5 (nadir) and the camera \#6 $\left(-26^{\circ}\right)$ does not occur around the 
critical angle (fig. 7). Rather, internal waves A, B, C and D exhibit an anisotropic contrast inversion which suggests more upwind mss contrast $d m_{u} / m_{u}$ than crosswind mss contrast $d m_{c} / m_{c}$. A good fit is obtained for $d m_{u} / m_{u} \simeq+3 \%$ and $d m_{c} / m_{c} \simeq+1 \%$. On the contrary, internal waves L, M, N, O and P exhibit more crosswind contrast, with a good fit obtained with $d m_{u} / m_{u} \simeq+1 \%$ and $d m_{c} / m_{c} \simeq+5 \%$.

a)

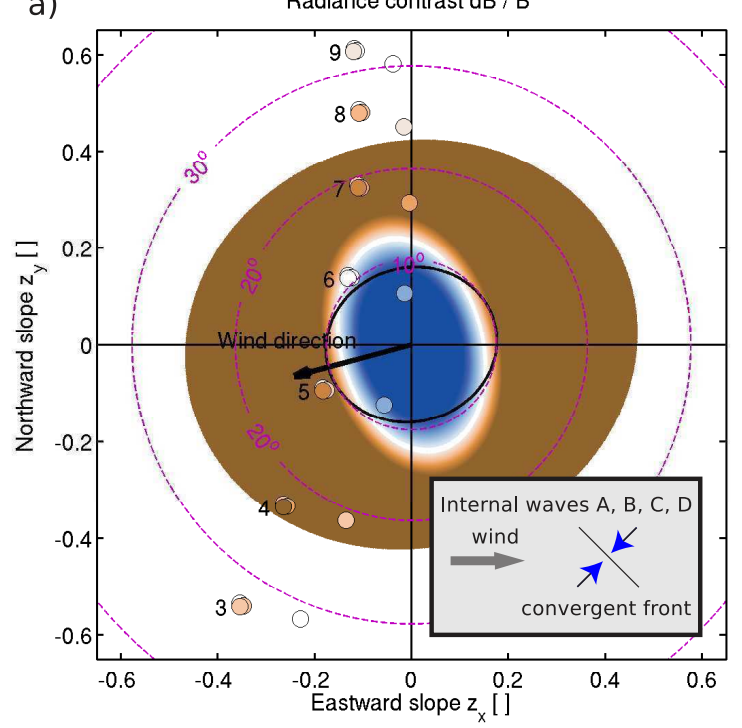

b)

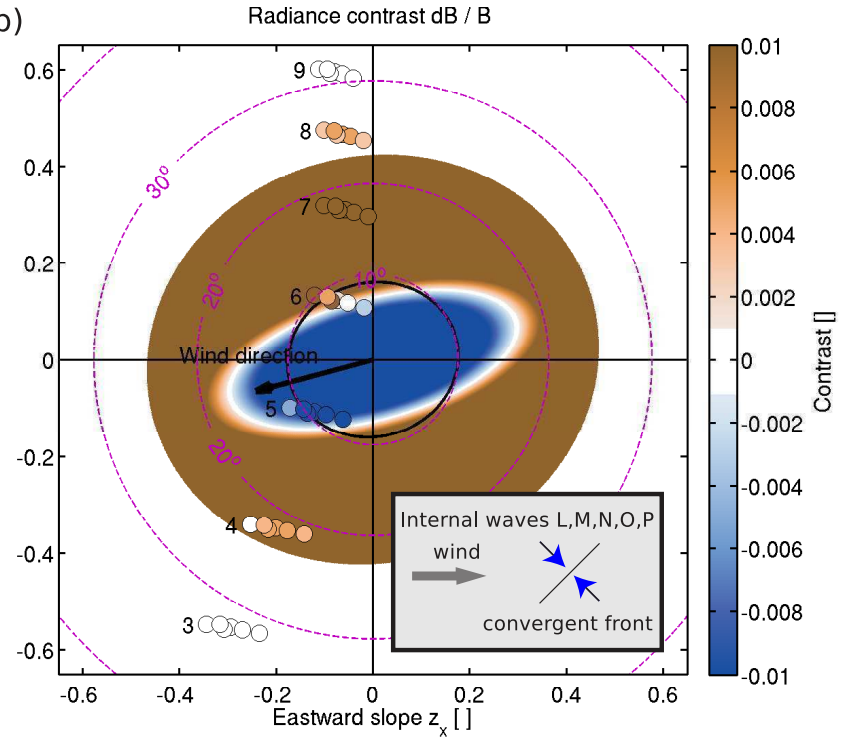

Figure 7: Synthesis of the radiance contrasts of the converging IW as function of the view angle. (a) Above the northeast/southwest propagating IW trains A, B, C, D. (b) Above the northwest/southeast propagating IW trains L, M, N, O, P. Setting the wind speed to 5 m s ${ }^{-1}$, a good fit is obtained with mss contrasts of (a): $+3 \%$ upwind and $+1 \%$ crosswind, and (b): $+1 \%$ upwind and $+5 \%$ crosswind.

\subsection{Consequences for mss contrast retrieval}

Considering that the mss contrast is isotropic (eq. 9) and neglecting the anisotropy can thus possibly lead to a significant misinterpretation and error in the precise estimation of the mss contrasts. This is illustrated in fig. 8 for the case of the internal waves $\mathrm{L}, \mathrm{M}, \mathrm{N}, \mathrm{O}$ and $\mathrm{P}$. The anisotropic mss contrasts inferred from multi-angle imagery are $d m_{u} / m_{u} \simeq+1 \%$ and $d m_{c} / m_{c} \simeq+5 \%$. Using a single-angle radiance contrast and inverting it to an isotropic mss contrast $d m / m$ (eq. 9) would then lead to significant differences compared to the exact mss contrast. Fig. 8 shows mss contrast overestimations in the crosswind direction and underestimations (and even inverted sign of the mss contrast) in the wind direction. The estimation is noticeably poor at zenith view angles $\theta_{r}$ close to $10^{\circ}$, with large overestimations. This illustrates the necessity to take into account anisotropic mss contrasts and to use multi-angle observations. 


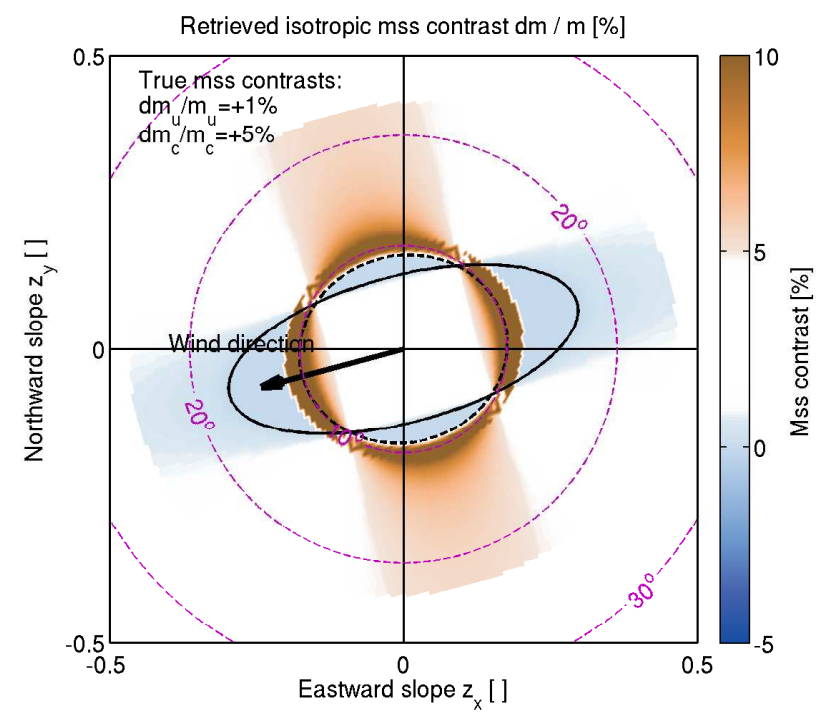

Figure 8: Estimated isotropic mss contrast $d m / m$ from a slope PDF with anisotropic contrasts $d P / P$. The PDF contrasts $d P\left(z_{x}, z_{y}\right) / P\left(z_{x}, z_{y}\right)$ are obtained from eq. 4 by setting the wind speed to $5 \mathrm{~m} \mathrm{~s}^{-1}$ and by setting the mss contrasts to $d m_{u} / m_{u}=+1 \%$ (upwind) and $d m_{c} / m_{c}=+5 \%$ (crosswind). This would correspond to the case of IW trains L, M, N, O, P shown in fig. 7b. For each slope $z_{x}$ and $z_{y}$, an isotropic mss contrast $d m / m$ is calculated with eq. 9 to reproduce the PDF contrast $d P\left(z_{x}, z_{y}\right) / P\left(z_{x}, z_{y}\right)$. The estimation obviously diverges near the ellipse of isotropic contrast inversion (dashed black line).

\subsection{Consequences for current gradient retrieval}

One of the main applications of surface roughness is to estimate the amplitude of the surface current gradient from the amplitude of the mss contrast. This is generally done using the conservation of wave action and inverting the mss contrast into a current gradient (see e.g. eq. 4 in Kudryavtsev et al., 2012a). Here we use the wave action conservation model of Kudryavtsev et al. (2005). We set the wind speed to $5 \mathrm{~m} \mathrm{~s}^{-1}$ with a direction orthogonal to the IW crest. The IW horizontal current $\mathrm{u}$ is specified as

$$
u=u_{0} \cos \frac{2 \pi(x-c t)}{\lambda} \exp -\left(\frac{5(x-c t)}{L}\right)^{2},
$$

where $x$ is the coordinate along the propagation direction, $t$ the time and $c$ the IW phase speed. $\mathrm{L}$ is set to $3 \mathrm{~km}$ to limit the group size to a few waves. The distance $\lambda$ between consecutive IW crests is set to $1 \mathrm{~km}$, as observed for IW trains $\mathrm{A}, \mathrm{B}, \mathrm{C}, \mathrm{L}, \mathrm{M}$ and $\mathrm{N}$. The phase speed is set to $c \simeq 1 \mathrm{~m} \mathrm{~s}^{-1}$, consistently with the phase displacement observed during the $7 \mathrm{~min}$ between the different MISR cameras. This phase speed is also consistent with the observed group distance of about $33 \mathrm{~km}$ (e.g. between groups A, B and C), leading to group speed $c_{g} \simeq 0.75 \mathrm{~m} \mathrm{~s}^{-1}$ if one supposes a semi-diurnal origin of the IW.

The model needs IW velocities $u_{0}$ in (18) of about $u_{0} \simeq 5 \mathrm{~cm} \mathrm{~s}^{-1}$ to produce mss contrasts of $d m_{u} / m_{u}=+1 \%$ (upwind) and $d m_{c} / m_{c}=+5 \%$ (crosswind).

Considering that the mss contrast is isotropic (eq. 9) and neglecting the anisotropy can lead to a significant error in the estimation of the current gradient. For instance, the isotropic mss contrast $\mathrm{dm} / \mathrm{m}$ can be overestimated to $5-10 \%$ in the upwind direction (fig. 8), leading to overestimation of the IW current to up to $u_{0} \simeq 20 \mathrm{~cm} \mathrm{~s}^{-1}$.

\section{Discussion}

\subsection{Sources of anisotropic mss contrasts}

There are many sources of mss contrasts: change of wind speed or direction, presence of surfactants, and direct wave-current interactions. The fig. 9 summarizes which sources are expected to produce isotropic mss contrasts: change of wind speed (see next section), surfactants, and current divergence. On the contrary, anisotropic mss contrasts 
are expected from changes in wind direction (see next section) as well as from anisotropic currents like fronts with current shear and diverging fronts (e.g. internal waves).

\begin{tabular}{|c|c|}
\hline Isotropic mss changes & Anisotropic mss changes \\
\hline - change of wind speed & - change of wind direction \\
- surfactants & - anisotropic currents \\
- current divergence & sheared front \\
\hline & $\leftarrow$
\end{tabular}

Figure 9: The different sources mss contrasts, classified whether they are thought to induce rather isotropic or anisotropic mss contrasts.

If sheared frontal currents with slanting wind are expected to create mss contrasts largely anisotropic (see sketches in fig. $2 \mathrm{a}$ and $2 \mathrm{~b}$ ), this was less expected from diverging frontal currents of IWs, which exhibit current gradients very close to isotropic divergence. It is suspected that anisotropic mss contrasts are mainly created by one component of the current gradient, the strain in the wind direction (Rascle et al., 2014, 2016). This should explain the differences observed between IW trains with orthogonal propagation directions (fig. 7a and b). However, the wind was slanting to the IWs, creating no strain in the wind direction but rather shear in the wind direction (see Rascle et al., 2016, their fig. 4, for more explanations on this current gradient decomposition). It is thus unclear what creates the mss anisotropic response to those IWs. Other possible candidates are a change of the major axes orientations (see next section), nongaussian effects (see next section), or non-local effects due to relative IW - surface waves propagations (see e.g. Thompson and Gasparovic, 1986). In addition to those wave-current interaction mechanisms, other candidates could also involve the presence of surface slicks on the leading edge of the IW, or a feedback of surface roughness on the wind field (e.g. Mitsuyasu and Honda, 1986). As mentioned, the MISR observations do not have sufficient angular discretization to clarify the matter with a precise detection of the contrast inversion zone for each individual IW train.

\subsection{Non-gaussian surface slope PDF}

We must emphasize that to first order, the PDF is supposed gaussian with the major axes in the upwind and crosswind direction. Considering short scale waves (less than $30 \mathrm{~cm}$ ), it is well known that associated surface slopes can become locally very steep and asymmetrical, leading to non-gaussian PDF, including skewness (Longuet-Higgins, 1982; Chapron et al., 2002) and kurtosis (Chapron et al., 2000; Munk, 2009). Further, note that correlations are reported between the occurrence of upwind steep slopes and the overall rise of crosswind slope variance. As such, increased or reduced numbers of breaker elements in frontal areas shall impact the resulting directionality of the slope PDF. The fig. 10 shows PDF contrasts, expected for a change of wind speed and of wind direction. In this plot, we relax the assumption of Gaussian PDF and we use the skewness and kurtosis estimated by Bréon and Henriot (2006). If the patterns resemble those described with the isotropic and antisymmetric modes, the exact location of the contrast inversion is modified. Further investigations of such effects are certainly necessary, but are beyond the scope of the present analysis. Future studies will await until further measurements, preferably airborne with high angular discretization - like those of fig. 2b or those of the Cloud Absorption Radiometer (CAR, Gatebe et al., 2011; Gatebe and King, 2016) - will be acquired over well instrumented areas. 

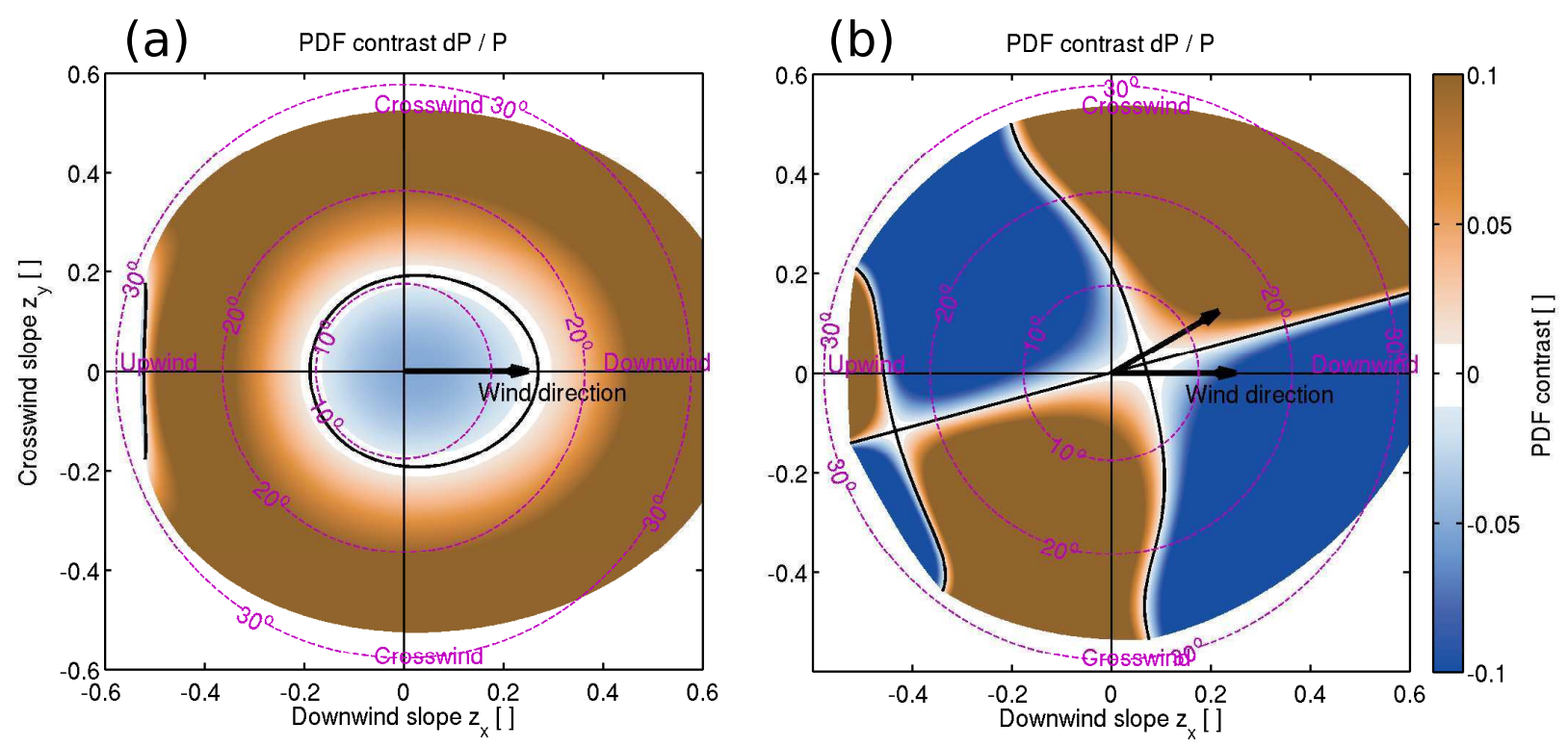

Figure 10: Surface slope PDF contrast $d P / P$ expected for (a) an increase of wind speed of $0.5 \mathrm{~m} \mathrm{~s}^{-1}$, (b) a rotation of wind direction by $30^{\circ}$. The wind is set to $9 \mathrm{~m} \mathrm{~s}^{-1}$. The PDF are not supposed gaussian but follow the Gram Charlier decomposition with the skewness and kurtosis measured by Bréon and Henriot (2006).

\subsection{Impact of skyglint and other sources of radiance}

Another strong assumption of the present work is that of negligible sources or radiance other than direct sunglint. As shown by Lin et al. (2016), the skyglint can make a non-negligible contribution to the background radiance, especially for radiometers in the blue or green channels. It is also the case for the water leaving radiance in those channels. In such case, the background radiance might be corrected as $B=B_{S u n G}+B_{c o r}$, with $B_{c o r}=B_{S k y G}+B_{W L}+B_{W C}$.

If one supposes that $B_{c o r}$ has a weak dependency on the sea state (i.e. on the mss), $d B_{c o r} \ll d B_{s u n G}$ and we have

$$
\frac{d B}{B}=\frac{d P}{P} \frac{B_{S u n G}}{B}
$$

which gives a small correction to eq. 5 .

It is expected that skyglint $B_{S k y G}$ has a relatively weak dependency on the sea state at low to moderate view angles $\theta_{v}$ (e.g. Cox and Munk, 1954, their fig. 4). The water leaving radiance $B_{W L}$ is also relatively independent on the sea state, but it is strongly affected by the particle content of the upper ocean, which can drastically change at oceanic fronts. Also, the contribution of whitecaps radiance $B_{W C}$ might become important (Frouin et al., 1996) as the whitecap coverage can drastically increase around oceanic convergent fronts. Investigation of those corrections are left for future studies, possibly using sensors with multiple polarization capabilities (e.g. Harmel and Chami, 2013).

\section{Future surface current missions}

Lastly, we illustrate how surface roughness measurements shall be used in the context of satellite remote sensing of currents at high resolution. Several techniques are available and/or are being proposed to observe surface currents at relatively low $(\sim 20 \mathrm{~km})$ resolution. Those include across-track altimetry, with the upcoming Surface Water and Ocean Topography (SWOT) mission (Fu et al., 2012) in 2021, high-frequency (e.g. Ka-band) real aperture radar techniques, like the proposed Sea Surface KInematics Multiscale monitoring (SKIM) concepts (Ardhuin et al., 2017a) and the Doppler scatterometer concept (Rodríguez et al., 2018), and multi-antenna Synthetic Aperture Radar (SAR) as proposed with the Wavemill concept (Buck, 2005; Martin and Gommenginger, 2017). Noise and viewing geometry of these instruments will generally require spatial averaging of the retrieved currents at about $20 \mathrm{~km}$. Those medium resolution currents will thus likely underestimate the surface current gradients occurring at smaller scales (fig. 11a). 
To complement those observations of absolute currents, surface roughness at high $(\simeq 750 \mathrm{~m})$ resolution contains information on the gradients at high resolution (fig. 11b). That information can be used to reconstruct high resolution current field (fig. 11c), especially improving location and gradients.

This resolution issue is illustrated in fig. 11 using numerical simulations of waves and currents over the Gulf Stream region. Currents are simulated using the Regional Ocean Modelling System (ROMS) at $750 \mathrm{~m}$ resolution in a realistic configuration. More details can be found in Gula et al. (2015). The waves are simulated using WaveWatch3 (WW3), also at $750 \mathrm{~m}$ resolution, and include wave-current interactions. More details can be found in Ardhuin et al. (2017b). The wind is set to $5 \mathrm{~m} \mathrm{~s}^{-1}$ from the NW. At a medium resolution of about $20 \mathrm{~km}$, currents are obiously largely smeared. The original and degraded currents are shown in fig. 11c and fig. 11a. The sharpness of the internal front of the Gulf Stream is largely lost, and original current gradients accordingly reduced. The colors in fig. 11 show the current gradient magnitude, calculated as $\sqrt{\left(\partial_{x} u\right)^{2}+\left(\partial_{y} u\right)^{2}+\left(\partial_{x} v\right)^{2}+\left(\partial_{y} v\right)^{2}}$, where $u, v$ are the surface current components in arbitrary $x, y$ horizontal directions.

The omnidirectional wave mss contrast is calculated as $d m / m$, with $d m$ the $20 \mathrm{~km}$ high-pass filtered mss. A threshold of the mss contrast is set to $2 \%$. Below this threshold, observations should contain instrument noise as well as roughness variations induced by wind variations (e.g. Kudryavtsev et al., 2005). Above this threshold, surface roughness contrasts contain the usable information about the current gradients. This information is sparse in space (fig. 11b). One view angle would provide the location of the intense current gradients, without information about their sign (divergence or shear or vorticity) and uncertainty on their magnitude. Multiple look angles, as proposed in the present work, would provide in addition the sign of the gradients and a more precise estimation of their magnitude, which information can be used to constrain a reconstruction of the currents at high resolution.

The design of a dedicated future mission to retrieve and precisely document surface currents at high resolution could thus build upon a satellite constellation, building from standard altimeter data, to medium resolution measurements (like SWOT or SKIM), completed with high resolution multi-angle instruments detecting surface roughness contrasts. One possibility for such high resolution instruments could be mono-static multi-antenna SARs (e.g. Wavemill), with polarization capabilities to help separating resonant scattering elements from wave breaking patches (Kudryavtsev et al., 2013, 2014). Another possibility could be multi-angle bi-static radiometers as proposed in the present work, combining a high angular discretization (like that of the future 3MI sensor, see fig. 5) and a very high spatial resolution (of the order of $10 \mathrm{~m}$ for Sentinel-2 (Kudryavtsev et al., 2017b) and $1 \mathrm{~m}$ for PRISM). The advantage of a very high spatial resolution would be the additional estimation of currents from maximum cross-correlation (MCC) techniques (e.g Warren et al., 2016), or more accurately, from precise wave phase velocities (Kudryavtsev et al., 2017b). Such multi-angle radiometers should also include polarization capabilities, which, as mentioned, help separating sunglint radiance $B_{S u n G}$ from water-leaving $B_{W L}$, skyglint $B_{S k y G}$ and whitecaps $B_{W C}$ radiances (Harmel and Chami, 2013), and help retrieving additionally the background wind field. 
(a) Low resolution Surface Current

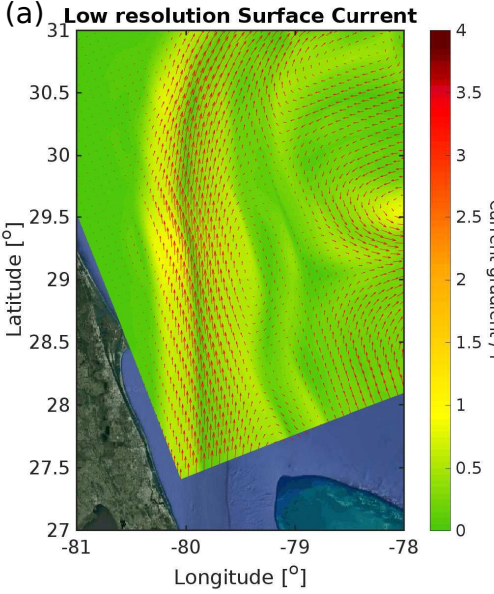

(b) High resolution Surface Roughness



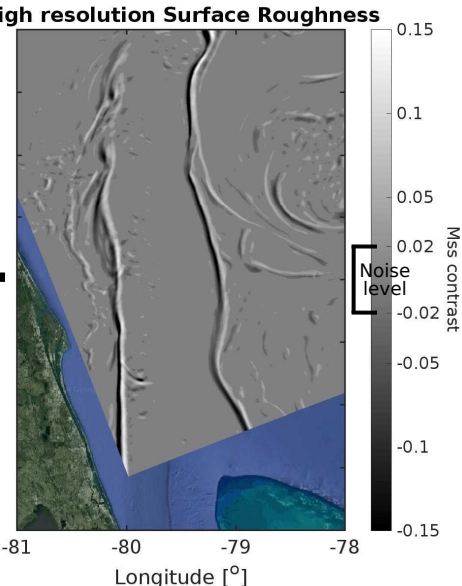

(c) High resolution Surface Current

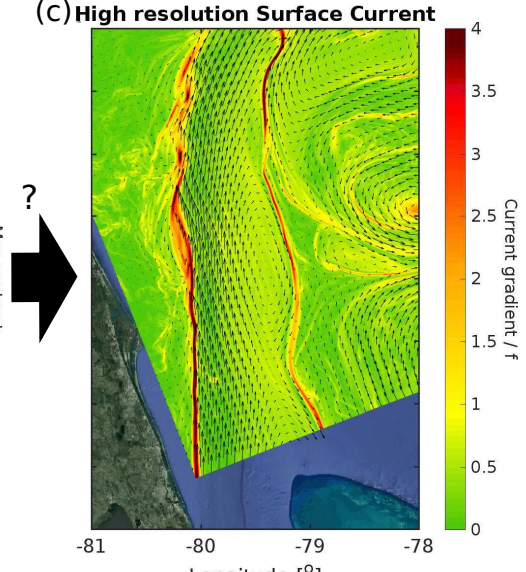

Figure 11: Numerical illustration of a strategy to observe high resolution currents from satellite. Panel (a) shows surface currents degraded to a resolution of $20 \mathrm{~km}$. Arrows are surface currents and colors are current gradient magnitude, normalized by the local Coriolis parameter $f$. Panel (b) shows the mss contrast $\mathrm{dm} / \mathrm{m}$ at a high resolution of $750 \mathrm{~m}$. The contrast is obtained by high-pass filtering $m$ at $20 \mathrm{~km}$. Only high values (>2\%) of the contrast are kept to mimic a filtering out of atmospheric effects and of instrument noise. Panel (c) shows surface currents at the original resolution $(750 \mathrm{~m})$.

\section{Conclusion}

Sunglint images of the sea surface provide highly powerful means to observe and quantify small-scale spatial variations of currents, wind and surfactants. All these fine-scale geophysical variations are indeed directly impacting measurable brightness contrasts. Since the first satellite sunglint images, it has been discussed that these geophysical features can appear with different signs of the brightness contrast, mainly depending on the zenith angle of light reflection at the time of the observations. To quantitatively interpret these ocean surface signatures, brightness changes must then be related to changes in slope properties of the locally impacted wave field.

To first order, a practical analysis framework can build on the classical concept of critical zenith angle, delimiting an area of contrast inversion in the center of the sunglint image. In this paper, we recalled the key hypothesis behind this classical concept of critical angle: the wave slope variance (mss) partitioning between its upwind and crosswind components is supposed to remain constant.

More in depth analysis and use of multi-angle sunglitter observations have recently evidenced that this assumption does not always hold, especially for mss variations induced by upper ocean anisotropic current gradients. Consequently, this paper proposes to shift from the classical one-dimensional (isotropic) mss interpretation towards a two-dimensional (anisotropic) interpretation, where the mss has two degrees of freedom, namely its upwind and crosswind components. As a result, to more unambiguously interpret upper ocean roughness signatures, single-angle sunglint images are no longer sufficient, and multi-angle sunglint observations are needed. As demonstrated in the present study with the MISR instrument, favorable multi-angle geometry can be obtained using existing multi-look radiometer instruments.

More field experiments are now required to better understand and model possible anisotropic mss (and more generally slope PDF variations) created by local wind and current changes. Those efforts shall help advance more direct quantifications of current gradients at high resolution from satellite and drone sunglint observations. It shall also open for new strategies to more consistently consider and combine high-resolution radar and optical satellite observations, including bi-static and multi-polarizations.

\section{Acknowledgments}

N.R. was supported by LabexMER via grant ANR-10-LABX-19-01 and is now supported by CIGOM (Consorcio de Investigación del Golfo de México). We also acknowledge the financial support from CNES (Centre National 
d'Etudes Spatiales), of the ANR (French Agence Nationale pour la Recherche) through the REDHOTS project, of the ESA (European Space Agency) through the STSE MESO3D project, the GlobCurrent project and the SARONG project. We acknowledge the use of The Atmospheric Science Data Center (ASDC) at NASA Langley Research Center for the MISR data. We also acknowledge the use of Worldview tool from NASA's EOSDIS. We also thank F. Collard at OceanDataLab for the fruitful discussions on this topic.

\section{References}

Apel, J. R., Byrne, H. M., Proni, J. R., Charnell, R. L., 1975. Observations of oceanic internal and surface waves from the Earth Resources Technology Satellite. Journal of Geophysical Research 80 (6), 865-881.

Ardhuin, F., Aksenov, Y., Benetazzo, A., Bertino, L., Brandt, P., Caubet, E., Chapron, B., Collard, F., Cravatte, S., Dias, F., Dibarboure, G., Gaultier, L., Johannessen, J., Korosov, A., Manucharyan, G., Menemenlis, D., Menendez, M., Monnier, G., Mouche, A., Nouguier, F., Nurser, G., Rampal, P., Reniers, A., Rodriguez, E., Stopa, J., Tison, C., Tissier, M., Ubelmann, C., van Sebille, E., Vialard, J., Xie, J., 2017a. Measuring currents, ice drift, and waves from space: the sea surface kinematics multiscale monitoring (skim) concept. Ocean Science Discussions 2017, $1-26$.

URL https: //www .ocean-sci-discuss.net/os-2017-65/

Ardhuin, F., Gille, S. T., Menemenlis, D., Rocha, C. B., Rascle, N., Chapron, B., Gula, J., Molemaker, J., 2017b. Small-scale open ocean currents have large effects on wind wave heights. Journal of Geophysical Research: Oceans 122 (6), 4500-4517.

Brannigan, L., 2016. Intense submesoscale upwelling in anticyclonic eddies. Geophysical Research Letters 43 (7), 3360-3369, $2016 \mathrm{GL067926.}$ URL http://dx.doi.org/10.1002/2016GL067926

Brannigan, L., Marshall, D. P., Naveira-Garabato, A., Nurser, A. G., 2015. The seasonal cycle of submesoscale flows. Ocean Modelling 92, 69-84.

Bréon, F., Henriot, N., 2006. Spaceborne observations of ocean glint reflectance and modeling of wave slope distributions. Journal of Geophysical Research: Oceans (1978-2012) 111 (C6).

Buck, C., 2005. An extension to the wide swath ocean altimeter concept. In: Geoscience and Remote Sensing Symposium, 2005. Proceedings. 2005 IEEE International. Vol. 8. IEEE, pp. 5436-5439.

Callies, J., Ferrari, R., Klymak, J. M., Gula, J., 2015. Seasonality in submesoscale turbulence. Nat. Commun. 6.

Chapron, B., Collard, F., Ardhuin, F., 2005. Direct measurements of ocean surface velocity from space: Interpretation and validation. J. Geophys. Res 110 (C07008).

Chapron, B., Kerbaol, V., Vandemark, D., Elfouhaily, T., 2000. Importance of peakedness in sea surface slope measurements. Journal of Geophysical Research 105 (C7), 17195-17202.

Chapron, B., Vandemark, D., Elfouhaily, T., 2002. On the skewness of the sea slope probability distribution. Gas Transfer at Water Surfaces, 59-63.

Chust, G., Sagarminaga, Y., 2007. The multi-angle view of misr detects oil slicks under sun glitter conditions. Remote sensing of Environment 107 (1), 232-239.

Cox, C., Munk, W., 1954. Measurement of the roughness of the sea surface from photographs of the sun's glitter. Journal of the Optical Society of America 44 (11), 838-850.

D’Asaro, E. A., Shcherbina, A. Y., Klymak, J. M., Molemaker, J., Novelli, G., Guigand, C. M., Haza, A. C., Haus, B. K., Ryan, E. H., Jacobs, G. A., Huntley, H. S., Laxague, N. J. M., Chen, S., Judt, F., McWilliams, J. C., Barkan, R., Kirwan, A. D., Poje, A. C., Özgökmen, T. M., 2018. Ocean convergence and the dispersion of flotsam. Proceedings of the National Academy of Sciences. URL http: //www .pnas .org/content/early/2018/01/09/1718453115

Dee, D., Uppala, S., Simmons, A., Berrisford, P., Poli, P., Kobayashi, S., Andrae, U., Balmaseda, M., Balsamo, G., Bauer, P., et al., 2011. The era-interim reanalysis: Configuration and performance of the data assimilation system. Quarterly Journal of the Royal Meteorological Society 137 (656), 553-597.

Diner, D. J., Bruegge, C. J., Martonchik, J. V., Ackerman, T. P., Davies, R., Gerstl, S. A., Gordon, H. R., Sellers, P. J., Clark, J., Daniels, J. A., et al., 1989. Misr: A multiangle imaging spectroradiometer for geophysical and climatological research from eos. Geoscience and Remote Sensing, IEEE Transactions on 27 (2), 200-214.

Ferrari, R., 2011. A Frontral Challenge for Climate Models. Science 332, 316-317.

Fett, R., Rabe, K., 1977. Satellite observation of internal wave refraction in the south china sea. Geophysical Research Letters 4 (5), $189-191$.

Frouin, R., Schwindling, M., Deschamps, P.-Y., 1996. Spectral reflectance of sea foam in the visible and near-infrared: In situ measurements and remote sensing implications. Journal of Geophysical Research: Oceans 101 (C6), 14361-14371.

Fu, L., Alsdorf, D., Morrow, R., Rodriguez, E., Mognard, N., 2012. SWOT: the Surface Water and Ocean Topography mission: Wide-swath altimetric measurement of water elevation on earth. Jet Propulsion Laboratory JPL-Publ 12-05, 1-228, available at http://hdl.handle.net/2014/41996.

Gatebe, C., Wilcox, E., Poudyal, R., Wang, J., 2011. Effects of ship wakes on ocean brightness and radiative forcing over ocean. Geophysical Research Letters 38 (17).

Gatebe, C. K., King, M. D., 2016. Airborne spectral brdf of various surface types (ocean, vegetation, snow, desert, wetlands, cloud decks, smoke layers) for remote sensing applications. Remote Sensing of Environment 179, 131-148.

Gatebe, C. K., King, M. D., Lyapustin, A. I., Arnold, G. T., Redemann, J., 2005. Airborne spectral measurements of ocean directional reflectance. Journal of the atmospheric sciences 62 (4), 1072-1092.

Gula, J., Molemaker, M., McWilliams, J., 2015. Topographic vorticity generation, submesoscale instability and vortex street formation in the gulf stream. Geophysical Research Letters 42 (10), 4054-4062.

Harmel, T., Chami, M., 2013. Estimation of the sunglint radiance field from optical satellite imagery over open ocean: Multidirectional approach and polarization aspects. Journal of Geophysical Research: Oceans 118 (1), 76-90.

He, X., Chen, N., Zhang, H., Guan, W., 2015. The brightness reversal of submarine sand waves in hj-1a/b ccd sun glitter images. Acta Oceanologica Sinica 34 (1), 94-99. 
Jackson, C., 2007. Internal wave detection using the moderate resolution imaging spectroradiometer (modis). Journal of Geophysical Research: Oceans $112(\mathrm{C} 11)$.

Jackson, C., Alpers, W., 2010. The role of the critical angle in brightness reversals on sunglint images of the sea surface. Journal of Geophysical Research: Oceans 115 (C9).

Johannessen, J., Chapron, B., Collard, F., Kudryavtsev, V., Mouche, A., Akimov, D., Dagestad, K., 2008. Direct ocean surface velocity measurements from space: Improved quantitative interpretation of Envisat ASAR observations. Geophysical Research Letters 35 (L22608), 6.

Johannessen, J., Kudryavtsev, V., Akimov, D., Eldevik, T., Winther, N., Chapron, B., 2005. On radar imaging of current features: 2. Mesoscale eddy and current front detection. Journal of Geophysical Research 110, C07017.

Kay, S., Hedley, J. D., Lavender, S., 2009. Sun glint correction of high and low spatial resolution images of aquatic scenes: a review of methods for visible and near-infrared wavelengths. Remote Sensing 1 (4), 697-730.

Klein, P., Lapeyre, G., 2009. The Oceanic Vertical Pump Induced by Mesoscale and Submesoscale Turbulence. Annu. Rev. of Marine Sci. 1, 351-375.

Kudryavtsev, V., Akimov, D., Johannessen, J., Chapron, B., 2005. On radar imaging of current features: 1. Model and comparison with observations. Journal of Geophysical Research-Oceans 110 (C7), C07016.

Kudryavtsev, V., Kozlov, I., Chapron, B., Johannessen, J., 2014. Quad-polarization sar features of ocean currents. Journal of Geophysical Research: Oceans $119(9), 6046-6065$.

Kudryavtsev, V., Myasoedov, A., Chapron, B., Johannessen, J. A., Collard, F., 2012a. Imaging mesoscale upper ocean dynamics using synthetic aperture radar and optical data. Journal of Geophysical Research: Oceans (1978-2012) 117 (C4).

Kudryavtsev, V., Myasoedov, A., Chapron, B., Johannessen, J. A., Collard, F., 2012b. Joint sun-glitter and radar imagery of surface slicks. Remote Sensing of Environment 120, 123-132.

Kudryavtsev, V., Yurovskaya, M., Chapron, B., Collard, F., Donlon, C., 2017a. Sun glitter imagery of ocean surface waves. part 1: Directional spectrum retrieval and validation. Journal of Geophysical Research: Oceans 122 (2), 1369-1383.

Kudryavtsev, V., Yurovskaya, M., Chapron, B., Collard, F., Donlon, C., 2017b. Sun glitter imagery of surface waves. part 2: Waves transformation on ocean currents. Journal of Geophysical Research: Oceans 122 (2), 1384-1399.

Kudryavtsev, V. N., Chapron, B., Myasoedov, A. G., Collard, F., Johannessen, J. A., 2013. On dual co-polarized sar measurements of the ocean surface. Geoscience and Remote Sensing Letters, IEEE 10 (4), 761-765.

La Violette, P. E., Peteherych, S., Gower, J. F. R., Mar 1980. Oceanographic implications of features in noaa satellite visible imagery. BoundaryLayer Meteorology 18 (2), 159-175.

URL https : //doi .org/10.1007/BF00121322

Lévy, M., Ferrari, R., Franks, P. J. S., Martin, A. P., Rivière, P., 2012. Bringing physics to life at the submesoscale. Geophys. Res. Lett. 39 (L14602).

Lin, Z., Li, W., Gatebe, C., Poudyal, R., Stamnes, K., 2016. Radiative transfer simulations of the two-dimensional ocean glint reflectance and determination of the sea surface roughness. Applied optics 55 (6), 1206-1215.

Longuet-Higgins, M. S., 1982. On the skewness of sea-surface slopes. Journal of Physical Oceanography 12, $1283-1291$.

Manolis, I., Grabarnik, S., Caron, J., Bézy, J.-L., Loiselet, M., Betto, M., Barré, H., Mason, G., Meynart, R., 2013. The metop second generation 3mi instrument. In: Sensors, Systems, and Next-Generation Satellites XVII. Vol. 8889. International Society for Optics and Photonics, p. 88890J.

Martin, A. C., Gommenginger, C., 2017. Towards wide-swath high-resolution mapping of total ocean surface current vectors from space: Airborne proof-of-concept and validation. Remote Sensing of Environment 197, 58-71.

Matthews, J., 2005. Stereo observation of lakes and coastal zones using aster imagery. Remote sensing of environment 99 (1), 16-30.

Matthews, J., Awaji, T., 2010. Synoptic mapping of internal-wave motions and surface currents near the lombok strait using the along-track stereo sun glitter technique. Remote Sensing of Environment 114 (8), 1765-1776.

Matthews, J. P., Yoshikawa, Y., 2012. Synergistic surface current mapping by spaceborne stereo imaging and coastal hf radar. Geophysical Research Letters 39 (17).

McClain, E. P., Strong, A. E., 1969. On anomalous dark patches in satellite-viewed sunglint areas. MONTHLY WEATHER REVIEW 60 (65), 70.

Mitsuyasu, H., Honda, T., 1986. The effects of surfactant on certain airsea interaction phenomena. In: Wave Dynamics and Radio Probing of the Ocean Surface. Springer, pp. 95-115.

Munk, W., 2009. An inconvenient sea truth: Spread, steepness, and skewness of surface slopes. Annual review of marine science 1, $377-415$.

Nagai, T., Tandon, A., Rudnick, D., 2006. Two-dimensional ageostrophic secondary circulation at ocean fronts due to vertical mixing and largescale deformation. Journal of Geophysical Research: Oceans 111 (C9).

Özgökmen, T. M., Beron-Vera, F. J., Bogucki, D., Chen, S. S., Dawson, C., Dewar, W., Griffa, A., Haus, B. K., Haza, A. C., Huntley, H., et al., 2014. Research overview of the consortium for advanced research on transport of hydrocarbon in the environment (carthe). In: International Oil Spill Conference Proceedings. Vol. 2014. American Petroleum Institute, pp. 544-560.

Perruche, C., Rivière, P., Lapeyre, G., Carton, X., Pondaven, P., 2011. Effects of surface quasi-geostrophic turbulence on phytoplankton competition and coexistence. Journal of marine research 69 (1), 105-135.

Rascle, N., Chapron, B., Ponte, A., Ardhuin, F., Klein, P., 2014. Surface roughness imaging of currents shows divergence and strain in the wind direction. Journal Of Physical Oceanography 44 (8), 2153-2163.

Rascle, N., Molemaker, J., Marié, L., Nouguier, F., Chapron, B., Lund, B., Mouche, A., 2017. Intense deformation field at oceanic front inferred from directional sea surface roughness observations. Geophysical Research Letters 44 (11), 5599-5608, 2017 GL073473.

URL http://dx.doi.org/10.1002/2017GL073473

Rascle, N., Nouguier, F., Chapron, B., Mouche, A., Ponte, A., 2016. Surface roughness changes by finescale current gradients: Properties at multiple azimuth view angles. Journal of Physical Oceanography 46 (12), 3681-3694.

Rodríguez, E., Wineteer, A., Perkovic-Martin, D., Gál, T., Stiles, B. W., Niamsuwan, N., Monje, R. R., 2018. Estimating ocean vector winds and currents using a ka-band pencil-beam doppler scatterometer. Remote Sensing 10 (4), 576.

SAF, O., 2013. Ascat wind product user manual. Tech. rep., SAF/OSI/CDOP/KNMI/TEC/MA/126, available on http://www. osi-saf. org.

Shcherbina, A. Y., Sundermeyer, M. A., Kunze, E., D’Asaro, E., Badin, G., Birch, D., Brunner-Suzuki, A.-M. E., Callies, J., Kuebel Cervantes, 
B. T., Claret, M., et al., 2015. The latmix summer campaign: Submesoscale stirring in the upper ocean. Bulletin of the American Meteorological Society $96(8), 1257-1279$.

Soules, S. D., 1970. Sun glitter viewd from space. Deep Sea Research and Oceanographic Abstracts 17 (1), $191-195$.

URL http://www.sciencedirect.com/science/article/pii/0011747170900987

Spall, M. A., 1995. Frontogenesis, subduction, and cross-front exchange at upper ocean fronts. Journal of Geophysical Research: Oceans 100 (C2), 2543-2557.

Thomas, L. N., Tandon, A., Mahadevan, A., 2008. Submesoscale processes and dynamics. Vol. 177. AGU, Washington, DC, pp. 17-38. URL http: //dx.doi.org/10.1029/177GM04

Thompson, D., Gasparovic, R., 1986. Intensity modulation in sar images of internal waves. Nature 320, 345-348.

Vandemark, D., Mourad, P., Bailey, S., Crawford, T., Vogel, C., Sun, J., Chapron, B., 2001. Measured changes in ocean surface roughness due to atmospheric boundary layer rolls. Journal of Geophysical Research: Oceans (1978-2012) 106 (C3), 4639-4654.

Warren, M., Quartly, G., Shutler, J., Miller, P., Yoshikawa, Y., 2016. Estimation of ocean surface currents from maximum cross correlation applied to goci geostationary satellite remote sensing data over the tsushima (korea) straits. Journal of Geophysical Research: Oceans 121 (9), 69937009.

Yang, K., Zhang, H., Fu, B., Zheng, G., Guan, W., Shi, A., Li, D., 2015. Observation of submarine sand waves using aster stereo sun glitter imagery. International Journal of Remote Sensing 36 (22), 5576-5592.

Zhong, Y., Bracco, A., 2013. Submesoscale impacts on horizontal and vertical transport in the gulf of mexico. Journal of Geophysical Research: Oceans 118 (10), 5651-5668. 